\title{
IS HIGHER EDUCATION IN THE UK BECOMING MORE COMPETITIVE?
}

\section{Andy Adcroft, Jon Teckman and Robert Willis}

Dr Andy Adcroft (corresponding author)

School of Management

University of Surrey

Guildford

GU2 7XH

Tel: $\quad 01483682007$

Fax: $\quad 01483685119$

E-mail: $\quad$ a.adcroft@surrey.ac.uk

Jon Teckman

Fletcher Teckman Consulting

Aylsebury

Buckinghamshire

Dr Robert Willis

Ashcroft International Business School

Anglia Ruskin University

Chelmsford

Essex 


\title{
IS HIGHER EDUCATION IN THE UK BECOMING MORE COMPETITIVE?
}

\begin{abstract}
Purpose

The aim of this paper is to consider the extent to which recent changes in the UK's higher education sector are likely to (a) increase the level of competition and (b) change the behaviour of UK higher education institutions Design

The paper draws on a conceptual framework developed to understand competitive conditions and behaviours in order to provide an analytical device to guide the narrative of the paper. The paper draws on a number of national and international sources.

Findings

It is likely that competition between UK higher education institutions will intensify in the future especially in light of the introduction of student tuition fees and this will lead to further changes in behaviour.

Originality/Value

The paper offers an original approach and conceptual basis to make a contribution to a growing debate about the future of the UK higher education sector
\end{abstract}




\section{Introduction}

The aim of this paper is to consider the extent to which recent changes, for example the introduction of variable tuition fees in 2006, in the UK's higher education sector are likely to give rise to increasing competition and whether such competition is likely to result in changes in the behaviour of higher education institutions. In discussing these issues, the paper hopes to contribute to a debate about how the sector may and can look in future. Central to the paper, therefore, is the issue of competition which is a broad reflection of one of the more enduring public sector problem definitions of the past 20 or 30 years; poor public sector performance is a product of poor public sector management and the solution to these problems is the creation of frameworks which mirror the private sector (Adcroft and Willis, 2005). Under this problem definition, it is not surprising that, since the early 1980s, the public sector has been subjected to interventions aimed at increasing competition through, for example, compulsory competitive tendering and the imposition of quasi-competition through internal markets and best value systems. This paper offers a different perspective. Much of the literature in this field, especially the literature on New Public Management (NPM), takes as its starting point the content of management practices introduced into the public sector whereas this paper takes the context of such management practices as its starting point. Our central argument is that higher education is different to many other areas in the public sector because it offers the prospect of real competition and that competition is likely to deliver significant changes in how universities are organised, managed and regulated. These changes offer significant challenges to all those who work in the higher education sector.

In making this argument the paper is organised in fairly straightforward manner. The next section provides a framework through which competition in higher education can be analysed and understood. This theoretical context focuses on a discussion of competitive behaviours and orientations and how they are influenced by the degree of real competition faced. Using criteria developed in this section, the paper next considers the extent to which there is growing competition in the higher education sector before discussing how that competition is affecting behaviour with specific reference to the development of a more competitive orientation. The paper concludes with a summary of the key points made and suggestions as to where the debate may move to next.

\section{Theoretical and Conceptual Grounding}

The theoretical foundation on which this paper is built is the assumption that organisations which operate in competitive environments behave in different ways to organisations which operate with the absence of competition. In orthodox economics, understanding firm behaviour in competitive markets is relatively simple: The price mechanism provides the means through which supply and demand find equilibrium and the firm best placed to provide goods or services at the market price triumphs. Economics is, however, less convincing in its explanation of why one firm wins out over others in the market. What may be more useful is the Structure-Conduct-Performance (SCP) framework which 
originated in industrial organisation economics and provides the foundation on which much of the literature on competitive strategy is built. Within this framework the main determinant of behaviour is the market and the extent to which the market delivers high or low levels of competition. For example, Porter (1996) suggests that strategy is the creation of a "unique and valuable position" (p.68) within a set of (largely) predetermined industry conditions. Classical strategy suggests that the outcome of competition is determined by the company with the best strategy; in the race to the ideal position, the winner is the company that has made the best choices about where and how to compete and has combined this with decisions about which activities will and will not be carried out (Porter, 1996).

In developing a framework to explain behaviours and outcomes in competitive circumstances, Adcroft and Teckman (2008a and 2008b) offer a perspective which combines elements of both economics and classical strategy. They argue that the outcome enjoyed by a firm in a competitive situation is the product of two key factors; the ability of that organisation to perform and the ability of that organisation to compete; firms will have a blend of competitive and performance orientations. How an organisation performs is essentially concerned with what happens within the boundaries of that organisation; its collection of activities and systems and the management practices employed. How an organisation competes, on the other hand, is more externally driven and is primarily concerned with how the organisation interacts with others in its chosen marketplace.

The first characteristic of a performance orientation is a focus internally. Individuals with a high performance orientation are "preoccupied with themselves and the way others perceive them" (Simons et al., 2000, p.336) and so, within organisations, there is a clear internal focus in terms of both what is done and how those activities should be recognised. Coad and Berry (1998) develop this point further and point out that recognition will be driven by peers within the organisation and this is further elaborated on by Coad (1999) who points out the importance of recognition within the organisation from those, for example, on whom advancement may depend. The second characteristic is the activities and beliefs that such an orientation would foster. Simons et al. (2000) argue that performance orientation is about establishing where competence lies and these competencies, according to Stiles et al. (1997) will tend to be managed through clear and strict measures where the focus is on optimisation through repetition, practice and rehearsal. Unsurprisingly, this orientation often leads to the avoidance of challenge, struggle, experiment and innovation (Coad and Berry, 1998) and tends to work best in environments where there is "a lack of novelty, complexity and open-endedness" (Coad, 1999, p.114).

The first factor which differentiates competitive from performance orientation is its focus; competitive orientation focuses externally on the market place and more explicitly on outcomes; Lyle (1997) suggests that performance orientation is about the development of potential for excellence and competitive orientation is about translating that potential into practice in a contested environment. Covin and Covin (1990) suggest that competitive orientation is a "general 
management disposition reflected in a firm's willingness to take on and desire to dominate competitors through a combination of proactive moves and innovative efforts" (p.36). This different focus leads to different activities and behaviours. Perry and Shao (2005) identify four key activities and behaviours which underpin a competitive orientation: There will be clear attention paid to the acquisition and dissemination of competitor information, more time will be spent attempting to predict competitor actions, more time will be spent attempting to influence competitors and resources will be allocated to the identification and exploitation of competitor weaknesses. These activities are summed up by Gatignon and Xuereb (1997) who suggest that a competitive orientation is about improvements to relative performance in order to secure a competitive advantage through innovation, challenge and risk-taking.

If, as the SCP model suggests, this kind of competitive behaviour is the result of external conditions, it is important to consider the conditions which would promote such behaviours. We would suggest six conditions which must be present, albeit in varying degrees, for such behaviours to be supported. First, there are choices available to the buyer or the user. Kelly (2003) suggests that this means that any buyer in a given market place has the "option to buy from a rival seller what we think of as the same product" (p.15) and he continues by arguing that this must mean real and practical choices rather than theoretical choices. Second, there are rewards for successful sellers or providers who are better able to offer the good or service than their competitors. For Kelly (2003) this translates into behaviours whereby there is "effort by each seller to equal or exceed the attractiveness of the others offerings" (p.15) Third, just as there are positive results for success in the contest, so too are there real consequences for failure and those sellers or providers who fail to meet the demands or needs of the buyers or users of that service. Fourth, information is available in a form that is usable to all parties in the contest, sellers and buyers, providers and users. For example, Savvides (2006) suggests that the ultimate efficiency of any market is determined by the amount of information available to all those present. Fifth, the actions of one player in the contest will have repercussions and cause reactions in other players and the environment will be in a reasonably constant state of flux and change. Boeker (1991) suggests that this means that the "success of one firm's strategy often depends on the actions of others" and "the response of a firm to the actions of its competitors can also have an important influence on performance" (p.613). Finally, there will be changes in behaviour as a result of the competitive conditions by both users and providers. Judging whether or not an area of the public sector will support competitive behaviour will, therefore, depend on these issues where "a satisfactory state of all malleable dimensions are required" (Kelly, 2003, p.16).

The logic of this is that the relationship between the content of management practices and the context in which they take place is crucial. This creates a set of both theoretical and practical challenges. Drucker (1995), for example, argues that "what one organisation does, any other organisation can do as well" (p.23) and this provides a clear rationale for the transfer of management practices between organisations and sectors. In a general public sector context, Lawler and Hearn (1995) point out that this "implies that there are certain core functions 
of management applicable across all organisational contexts and that certain management techniques can be transferred across contexts - in this case, from the private to the public sector" (p.9). The frequent response to this has been that only content is being imported and, because the context is fundamentally different, it is doomed to fail. We now turn to applying this framework to the UK higher education sector.

\section{Are competitive conditions changing in Higher Education?}

The focus of this section of the paper is in examining the extent to which the competitive landscape of higher education is changing and the degree to which the preconditions for competitive behaviours discussed in the previous section are being met. In particular, the section focuses on the shift in policy in 2006 from flat to variable tuition fees for undergraduate students. This shift was rationalised in a number of ways. For example, the DfES (2004b) suggested that it was part of a strategy built on the notion of diversity of provision because "it is wrong to assume that every student wants the same thing" (p. 4) and variable fees would better differentiate types of university provision. This view has support internationally. For example, CHEPS (2006), in discussing the future of Dutch higher education, reviewed the impact of variable fees internationally and found that they were a "helpful" mechanism which "facilitates quality differentiation" (p. 68). Whilst there are clearly implications for finance and access, issues which have dominated the post-2006 debate, we would argue that the most important objective of variable fees has been the introduction of competition into the sector. Lawson (2006), for example, argues that variables fees were chosen as a policy mechanism because "they most resembled the operation of a market" (p. 1) and Temple et al. (2005) argued for the benefits of variable fees as increasing income and increasing quality both delivered by "new market pressures" (p. 7).

Financially, the impact of variable fees may be limited; the main contributor to university finance will remain the government and, in any case, even with a maximum fee of $£ 3,000$, across most areas of study the full costs of tuition will not be met by student fees (DfESa, 2004). The question, therefore, must be asked as to what will be the impact of tuition fees? Our argument is that discussion of variable tuition fees should be framed in terms competition; will they further alter the competitive landscape of higher education and, in doing so, contribute to changes in the behaviour of universities? In answering this question we would begin by pointing out that this is one of the main aims of government policy in introducing variable fees in the first place; "variable fees have been a major system change that will help deliver reform through the power it gives to student choice and the responsibility it places on providers to respond to that choice" (HM Government, 2004, p. 98). The words and language which promote variable fees are similar in tone and content to that which has promoted competition elsewhere in the public sector so why might it be more successful in higher education? Our answer to this is twofold. First, the preconditions for competitive behaviour are more readily met in higher education than elsewhere and, second, the main hurdles to competitive behaviour are absent across much of the higher education sector. 
In making a series of international comparisons, CHEPS (2006) suggest that student participation in higher education is a product of consumption and investment; consumption is the learning experience enjoyed by students and investment is the returns from that experience in the careers of graduates ( $p$. 35). CHEPS (2006) argument is simply that "competition will intensify" (p. 45) through, for example, globalisation, and that variable tuition fees will be the key element in how students navigate their way through these choices. As an exemplar of this, CHEPS (2006) discuss the American system and this view is supported by Davis (2006) who suggests that the "system is delivering the goods" as a result of the diversity and choice available to students (pp. 6-7). In discussing the impact of variable tuition fees on choice, our argument is not that they will either extend or reduce choices available to prospective students but rather that they will change the nature of choices made. The international evidence presented earlier suggests that the impact of fees will be on the perception of quality and it is, therefore, a realistic assumption to make that students will increasingly behave as rational consumers making trade-offs between price/cost and quality. Marginson (2004) discusses this in terms of "status competition" (p.186) and suggests that it leads to competition between institutions to attract students and competition between students to secure places in the best universities. Our suggestion is that this is likely to intensify in the future as the cap on variable fees is either raised or removed entirely and universities start to charge fees at different levels. There is a wide body of international evidence of how this is likely to change the sector. For example, Meek (2003) discusses the Australian experience of the burden of cost shifting from government to the individual and draws attention to the different types of decision making on the part of students and changes to the degree of institutional diversity.

Coupled with increasing choice for students is the growth in information available to students on which choices can be made. Rolfe (2003), for example, draws attention to the growing important of league tables, admission requirements, degree classifications and employability measures in student decision making (p. 45) and CHEPS (2006) suggest that, internationally, the most transparent and, therefore, competitive markets in higher education are likely to be found in the UK and USA. One of the most prominent issues in reforms to the public sector in general over the past few decades has been the growth in performance measurement and the use of such measurements for public purposes. This has manifested itself in a whole series of league tables for many public services from waiting times in hospital emergency rooms to diversity measures for the fire service. In higher education there are a number of different mechanisms through which this information is gathered and disseminated and it is this information which may inform student decision making and behaviour as well as institutional policy. For example, the Higher Education Academy (HEA) (2008) suggests that the National Student Survey (NSS) has had a significant impact on growing levels of student satisfaction through the attention paid in areas such as assessment and feedback and this attention is crucial to maintaining recruitment levels. Similarly Morgan (2004) suggests that the Research Assessment Exercise (RAE) is a crucial mechanism in identifying to the outside world the quality of research carried out in UK universities. 
Yelland (2006) has argued that the main result of increased choice is that higher education providers must spend more time understanding, and responding to, their local, national and regional markets as the market will become increasingly unforgiving for those who fail to be competitive. Lawson (2006) reinforces the notion of competition with consequences in higher education by suggesting that the future is about the "survival of the fittest" and this view is supported by Ward and Douglass (2006) who argue that the processes will, if anything, intensify in the future as "fee income will need to be an increasingly large component of the funding of higher education" (p. 2). Of all the preconditions for competitive behaviour, however, the rewards for success and consequences of failure are probably the two most difficult to assess. This is for two reasons. First, it is simply too early to tell. At the time of writing, variable fees have been in operation for less than three years and there still exists significant government control over their level. The market, therefore, has not yet had time to form let alone operate. The second reason is that rewards and consequences will probably be as much a political decision as a market decision. For example, in discussing this issue in the context of the NHS, Lewis and Gillam (2003) suggested that politicians, rather than market forces, created incentives which ended up as "weak or perverse" (p.78) and Glennerster (1998) argues that "politicians do not find it easy to let a public hospital go bankrupt" (p.405). The question for higher education would be whether or not politicians would show the same levels of squeamishness when faced with market failure in the university sector. The paper now turns to discuss the extent to which these changes in competitive conditions are reflected in changes in competitive behaviour.

\section{Is there a change in competitive behaviour?}

Changing behaviour in higher education is not a new issue, it has been happening for a number of years through, for example, changes which have taken place as the sector has shifted from an elite to a mass system. The result of this is that it is probably impossible to isolate specific behavioural changes which have occurred as a direct result of the introduction of variable tuition fees. It is, though, possible to assess the extent to which more competitive orientations and behaviours are becoming apparent in the UK higher education sector as a whole. This section of the paper deals with these issues in three ways: First, by considering it in the wider context of changes in public sector management over a number of decades and identifying why competition may be more successful in higher education than in other parts of the public sector; Second, by considering some of the more recent manifestations of a competitive orientation which is continuing to seep into higher education; Third, by offering some informed speculation on what the impact of such behaviour is likely to be on the sector in the UK.

Placing changes in higher education into a wider context of changes in the public sector overall, raises the obvious issue of New Public Management (NPM). Hood (1991, pp 4-5) suggests that NPM consists of a number of different doctrines which are blended and mixed according to the specific public sector circumstances under discussion. These doctrines include more emphasis on 
"professional" management, the introduction of explicit measures of performance, a focus on outputs and results and an ever greater role played by "private sector styles" of management practice. Ferlie and Steane (2002) suggest that all this boils down to "managers, markets and measurement" (p. 1461). Hood (1991, p. 5) suggests that this represents the marriage of "administrative reform" with "business type managerialism" and represents private sector management imported into the public sector. Furthermore, Hood (1991) suggests that it reflects an "international agenda" (p.3) for public sector reform with similarities in reform across much of the developed world. For example, Walshe (2001) identified rising costs, advancing technology and increasing public expectations as common issues across many public sectors internationally and this is reflected in common policy interventions across western Europe, north America and Australasia (Ferlie and Steane, 2002).

The most frequent criticism of these changes in the public sector centres on the appropriateness of private sector management practices. The crux of the argument tends to be that public and private sectors are fundamentally different and so it is impossible to transfer practices from one to the other. For example, McNulty and Ferlie (2002) argue that the lack of impact of Business Process Reengineering (BPR) in public sector contexts is due to the incorrect assumptions of BPR as being "apolitical and acultural" (p. 32) and this point is reinforced by Hood (1991) who questions the "claim to universality" (p. 8) of such practices. Both studies highlight differences in values between the private sector and a public sector which lacks the "bottom line ethic" (Hood, 1991, p. 10) as the main causes of relative failure. Ferlie and Steane (2002) argue, therefore, that "standards derived from the private sector" run the risk of "distorting the raison d'etre of each actor" in the public sector (p. 1460).

In considering the recent history of public sector reform in the UK, Paton (2006) suggests that the introduction of competition is a common theme as this is the mechanism which is most likely to deliver "an amalgam of increased efficiency and quality" (p.558). The most common explanation for this failure to transform is that the changes implemented have not been of a significant enough magnitude to overcome a set of structural handicaps to real competition. For example, in the National Health Service in the UK reform has not offered real choices for users because of a limited number of providers in local areas (see, for example, Talbot, 2001 and Baggott, 1997) and because users do not pay directly for services accessed (see, for example, Le Grand, 2003 and Painter, 1999). One of the questions raised by this paper, however, is the extent to which this holds true in higher education.

Soderland et al (1997) suggest three objectives which have driven reform in the UK public sector: Increasing competition between the providers of services; changes in the style and form of management practices; more discretion on the part of users in terms of the services they access. Our argument is that all three of these objectives are likely to be met and the introduction of variable tuition fees in 2006 further facilitated and, probably, accelerated this. Davies (2006) suggests that this introduction was driven by the need for UK universities to become more competitive in international markets, especially against 
universities from the USA. He attributes the current lack of competitiveness to long term underfunding which has happened at the same time as significant expansions in provision. In meeting the international challenge, the government delivered a strategy based on two key elements (DfES, 2004a). First, there was to be significant increases in funding, mainly through central grants but also through student contributions. Second, universities were to be made "free to take responsibility for their own strategic and financial future" (p. 76). Central to this was that students should now pay for the "benefits they get from higher education" (p. 76) and this was to be through tuition fees.

All this suggests that the degree of inter-connectedness amongst UK universities is growing where decisions within universities cannot be isolated and abstracted from decisions taken in other universities. In discussing the nature of competitive strategy, Walker (2003) provides a perspective which suggests that decisions are taken on the basis of either working with or working against other organisations in the marketplace and this is reflected in, amongst other things, a growing trend towards mergers and acquisitions in the Higher Education sector. Harman and Harman (2008), for example, identified 12 mergers of institutions in the UK between 1992 and 2006 and suggest that they are driven by "an increasingly competitive global market for higher education services" (p.99). They go on to suggest that this type of behaviour is likely to increase as competition provides "inducements for various kinds of partnership between universities" (p.118). Again there is support internationally for this view; Ward and Douglass (2006), for example, look at the impact of variable fees in the US and EU and suggest that restructuring and reorganisation of the sector is a likely outcome of their introduction.

What are likely to be the significant alterations in behaviour across the sector as a result of these forces and changes? In the area of business and management, for example, Adcroft and Dhaliwal (2009) identify two opposing perspectives in the development of business and management schools. At one end of the spectrum is the humanist tradition whereby knowledge generated and disseminated to students is valuable in and of itself. At the other extreme is a more utilitarian view which suggests that the role of business and management schools in universities is to generate and disseminate knowledge that is of practical value to the outside world. This mirrors the view of Hakala and Ylijoki (2001) who suggest that research is becoming less theoretical and more practically oriented and Pfeffer and Fong (2002) who suggest that such schools need to shift away from traditional academic models. Starkey and Tempest (2005) suggest that there are major shifts in behaviour underway as academics in business and management fields become less theoretical and more practical in outlook. We would, reasonably, speculate that the forces driving business and management schools in this direction are likely to have a similar effect on other disciplines across the sector.

\section{Conclusion}

The theory and evidence provided in this paper suggests that the higher education sector in the UK will be shaped and influenced in the future by a set of 
powerful forces, many of which have competition at their core and many of which will be exacerbated by the introduction of variable tuition fees. Whilst we would not suggest that the effect on university finances and access will not be significant, our argument has been that the most important impact of the introduction of variable tuition fees is increasing levels of competition. The most obvious outcome of all this is that universities will increasingly adopt a competitive orientation which will make issues such as management, performance measurement, globalisation, mergers, acquisitions and partnerships become ever more prevalent in the sector. This conclusion is consistent with the international evidence presented of sectors with more experience of variable tuition fees where competition between students and institutions has become part of the everyday vocabulary of universities.

There was probably never a time in higher education when moth and rust did not corrupt or when academic work was completely unsullied by commodification, competition and managerialism. In this paper we have avoided looking backwards to write an elegy for the passing of a golden age of academia and we have steered clear of offering emphatic dogmas about how the future might look. The paper has, hopefully, contributed to a debate about the future of the sector and how the sector may and can look in the future and in doing this our intention was to offer a disinterested observation of changes that are taking place and offer an interpretation of where they may take higher education in the future. The obvious implication of the discussion and evidence presented is that the future of the sector in the UK will be very different to the past and that a more competitive future will bring gains as well as losses for all stakeholders. The sooner that future is debated, influenced and even determined by academics from all disciplines the better.

\section{References}

Adcroft, A. and Willis, R. (2005) The (un)Intended Outcome of Performance Measurement in the Public Sector in The International Journal of Public Sector Management Volume 18, Number 5, 386-400.

Adcroft, A. and Teckman, J. (2008a) Performing and Competing: Using sport to understand the outcome of contests in Journal of Business Strategy volume 29 , number $5,38-44$.

Adcroft, A. and Teckman, J. (2008b) Theories, Concepts and the Rugby World Cup: Using management to understand sport in Management Decision volume 46, issue 4, 600-625.

Adcroft, A. and Dhaliwal, S. (2009) Disconnections in Management Theory and Practice: Poetry, numbers and postmoderism in Journal of Management Philosophy, volume 7, number 3, 61-69.

Baggott, R. (Summer 1997) Evaluating Health Care Reform: The case of the NHS internal market in Public Administration, volume 75, 283-306.

Boeker, W. (1991) Organisational Strategy: An ecological perspective

in The Academy of Management Journal, volume 34, number 3, 613-635.

CHEPS (2006) Higher Education Reform: Getting the incentives right, CPB Netherlands Bureau for Economic Policy Analysis, University of Twente. 
Coad, A. F. and Berry, A. J. (1998) Transformational leadership and learning orientation in Leadership and Organisational Development Journal, volume 19, number 3, 164-172.

Coad, A. F. (1999) Some survey evidence on the learning and performance orientations of management accountants in Management Accounting Research, volume 10, 109-135.

Covin, J. G. and Covin, T. J. (1990) Competitive Aggressiveness, Environmental Context and Small Firm Performance in Entrepreneurship Theory and Practice, Summer, 35-50.

Davies, H. (2006) Globalisation and the Future of Universities, University of Mumbai Santa Cruz.

Department for Education and Skills (2004a) White Paper: The Future of Higher Education, HMSO, London London.

Department for Education and Skills (2004b) Why not a fixed fee?, DfES,

Drucker, P. F. (1995) The Information Executives Truly Need in Harvard Business Review, volume 73, issue 1, 1-24.

Ferlie, E. and Steane, P. (2002) Changing Developments in NPM in The International Journal of Public Administration, volume 25, number 12, 14591469.

Gatignon, H. and Xuereb, J-M. (February 1997) Strategic Orientation of the Firm and New Product Performance in Journal of Marketing Research, volume 34, 77-90.

Glennerster, H. (1998) Competition and quality in health care: the UK experience in International Journal for Quality in Health Care, volume 10, number 5, 403-410.

Hakala, J. and Ylijoki, O. (2001) Research for Whom? Research orientations in three academic cultures in Organization, volume 8, 373-380.

HM Government (2004) Department for Education and Skills: Five year strategy for children and learners, Department for Education and Skills.

Harman, G. and Harman, K. (2008) Strategic Mergers of Strong Institutions to Enhance Competitive Advantage in Higher Education Policy, volume 21, 99-121.

Hood, C. (1991) A Public Management for All Seasons in Public Administration, Spring, volume 69, 3-19.

Kelly, J.M. (2003) The Missing Manifesto: What economists should be saying about electric utility restructuring in the United States in The Electricity Journal, January-February, 13-24.

Lawler, J. and Hearn, J. (1995) UK Public Sector Organisations: the rise of managerialism and impact of change on social services departments in The International Journal of Public Sector Management, volume 8, number 4, 716.

Lawson, N. (2006) Market logic turns a degree into a share certificate in The Guardian, $10^{\text {th }}$ August.

Le Grand, J. (2003) Motivation, Agency and Public Policy: Of knights and knaves, pawns and queens, Oxford University Press

Lewis, R. and Gillam, S. (2003) Back to the Market: yet more reform of the National Health Service in International Journal of Health Services, volume 33 , number $1,77-84$. 
Lomas, L. (2002) Does the development of mass education necessarily mean the end of quality? in Quality on Higher Education, volume 8, number 1, 71-79.

Lyle, J. W. B. (1997) Managing excellence in sports performance in Career Development International, volume 2, number 7, 314-323.

Marginson, S. (2004) Competition and Markets in Higher Education: a 'glonacal' analysis in Policy Futures in Education, volume 2, number 2, 175-244.

McNulty, T. and Ferlie, E. (2002) Re-engineering Healthcare: The complexities of organisational transformation, Oxford University Press, UK.

Meek, V. L. (2003) Governance and Management of Australian Higher Education: Enemies within and without, Springer, Sydney, Australia.

Morgan, K. J. (2004) The Research Assessment Exercise in English Universities 2001 in Higher Education, volume 48, 461-482.

Painter, C. (1999) Public Service Reform from Thatcher to Blair: A Third Way in Parliamentary Affairs, volume 52, number 1, 94-112.

Paton, C. (2006) The Changing Political Economy of the NHS in Public Finance and Management, volume 6, number 4, 539-577.

Perry, M. L. and Shao, A. T. (2005) Incumbents in a dynamic internet related services market: Does customer and competitive orientation hinder or help performance? In Industrial Marketing Management, volume 34, 590601.

Pfeffer, J. and Fong, C. (2002) The end of business schools? Less success than meets the eye in Academy of Management Learning and Education, volume 1, 78-95.

Porter, M. (1996) What is Strategy? in Harvard Business Review, November-December, 61-78.

Porter, P. and Vidovich, L. (2000) Globalisation and Higher Education Policy in Educational Theory, volume 50, issue 4, 449-466.

Rolfe, H. (2003) University strategy in an age of uncertainty: The effect of higher education funding on old and new universities in Higher Education Quarterly, volume 57, number 1, 24-47.

Savvides, S. (2006) The E-conomics of Information: SI the internet the great information equalizer? in International Journal of Computing and Information Sciences, volume 4, number 1, 9-21.

Simons, J., Dewitte, S. and Lens, W. (2000) Wanting to have vs. wanting to be: The effect of perceived instrumentality on goal orientation in British Lournal of Psychology, volume 91, 335-351.

Soderland, N., Csaba, I., Gray, A., Milne, R. and Raftery, J. (1997) Impact of the NHS reforms on English hospital productivity: an analysis of the first three years in British Medical Journal, number 7116, volume 315, 1126-1129.

Starkey, K. and Tempest, S. (2005) The future of the business school: knowledge challenges and opportunities in Human Relations, volume 58, number 1, 61-82.

Stiles, P., Gratton, L., Truss, C., Hope-Hailey, V. and McGovern, P. (1997) Performance management and the psychological contract in Human Resource Management Journal, volume 7, number 1, 57-66.

Talbot, C. (2001) UK public services and management (1979-2000): Evolution or revolution? in International Journal of Public Sector Management, volume 14, number 4, 281-303. 
Temple, P., Farrant, J. and Shattock, M. (2005) New Variable Fee Arrangements: Baseline institutional case studies for the independent commission, Institute of Education, University of London.

Walker, G. (2003) Modern Competitive Strategy, McGraw Hill, London, UK.

Walshe, K. (2001) Don't try this at home: Health policy lessons for the NHS from the United States, Institute of Economic Affairs, Blackwell Publishers, UK.

Ward, D. and Douglass, J. A. (2006) Higher Education and the Spectre of Variable Fees: Public policy and institutional responses in the United States and the United Kingdom in Higher Education Management and Policy, volume 18, number 1, 1-28.

Yelland, R. (2006) Trends in the global higher education market, OECD Directorate for Education. 